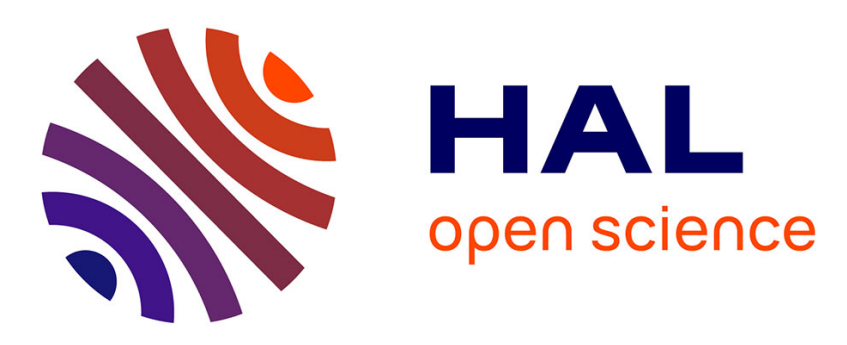

\title{
Numerical modelling of a composite fuselage manufactured by liquid resin infusion
}

Adrien Perret, Sebastien Mistou, Louis Etienne Denaud, Thierry Molle, Claudia Veyrac, Moussa Karama

\section{- To cite this version:}

Adrien Perret, Sebastien Mistou, Louis Etienne Denaud, Thierry Molle, Claudia Veyrac, et al.. Numerical modelling of a composite fuselage manufactured by liquid resin infusion. Applied Mechanics and Materials, 2011, vol. 62, pp.49-56. 10.4028/www.scientific.net/AMM.62.49 . hal-00840556

\section{HAL Id: hal-00840556 https://hal.science/hal-00840556}

Submitted on 3 Jul 2013

HAL is a multi-disciplinary open access archive for the deposit and dissemination of scientific research documents, whether they are published or not. The documents may come from teaching and research institutions in France or abroad, or from public or private research centers.
L'archive ouverte pluridisciplinaire HAL, est destinée au dépôt et à la diffusion de documents scientifiques de niveau recherche, publiés ou non, émanant des établissements d'enseignement et de recherche français ou étrangers, des laboratoires publics ou privés. 


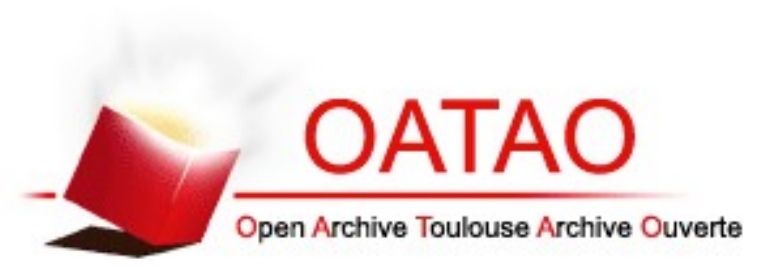

\section{Open Archive Toulouse Archive Ouverte (OATAO)}

OATAO is an open access repository that collects the work of Toulouse researchers and makes it freely available over the web where possible.

This is an author-deposited version published in: http://oatao.univ-toulouse.fr/ Eprints ID: 8923

To link to this article: DOI:10.4028/www.scientific.net/AMM.62.49 http://dx.doi.org/10.4028/www.scientific.net/AMM.62.49

\section{To cite this version:}

Perret, Adrien and Mistou, Sebastien and Denaud, Louis Etienne and Molle, Thierry and Veyrac, Claudia and Karama, Moussa Numerical modelling of a composite fuselage manufactured by liquid resin infusion. (2011) Applied Mechanics and Materials, vol. 62 . pp.49-56. ISSN 16627482

Any correspondence concerning this service should be sent to the repository administrator: staff-oatao@listes-diff.inp-toulouse.fr 



\title{
Numerical modelling of a composite fuselage manufactured by Liquid Resin Infusion
}

\author{
Adrien Perret ${ }^{1,2, a}$, Sébastien Mistou ${ }^{2, b}$, Louis-Etienne Denaud ${ }^{2}$, \\ Thierry Mollé ${ }^{1}$, Claudia Veyrac ${ }^{1}$ and Moussa Karama ${ }^{2}$, \\ ${ }^{1}$ DAHER-SOCATA, Aéroport Tarbes-Lourdes-Pyrénées, 65290 LOUEY, France \\ ${ }^{2}$ ENIT-LGP/IUT-ICA, PRES Université de Toulouse, Av. Azereix, BP1629, 65016 TARBES, France \\ aAdrien.Perret@enit.fr, ${ }^{\mathrm{b}}$ Sebastien.Mistou@enit.fr
}

Keywords: Structural composites, fracture, buckling, failure criterion, modelling.

\begin{abstract}
FUSCOMP (FUSelage COMPosite) is a Research \& Development program which has received the label from the Aerospace Valley competitiveness cluster. It will lead to a test of a composite fuselage demonstrator manufactured by the Liquid Resin Infusion (LRI) process. LRI is based on the moulding of high performance composite parts by infusing liquid resin on dry fibers instead of prepreg fabrics. The study of this proof of concept is based on the TBM 850 airframe, a pressurized business turboprop aircraft currently produced by DAHER-SOCATA. Technical achievements will concern numerical methods and finite elements analysis to be used for the modelling of this aircraft composite fuselage structure.

Actual industrial projects face composite integrated structure issues as a number of structures (stiffeners,...) are more and more integrated onto the skins of aircraft fuselage. Indeed the main benefit of LRI is to reduce assembly steps which lead to cycle time gain and thus cost reduction. In particular, infusing components and sub-components at the same time avoids riveting parts altogether. However it is necessary to validate the dimensioning of the studied composite structure.
\end{abstract}

\section{Notations}

\begin{tabular}{|c|c|c|c|}
\hline$A_{s w}$ & area of the stiffener web & $P_{c r}$ & critical buckling load of a \\
\hline$a, b$ & panel length, panel width & $P_{e}$ & Euler buckling load \\
\hline$D$ & bending stiffness matrix & $R F_{i}$ & $\begin{array}{l}\text { Reserve Factor, } \\
i=\mathrm{cb}, \mathrm{cs}, \mathrm{pb}, \mathrm{sb}, p x, p x y, w x\end{array}$ \\
\hline$D_{i j}$ & $\begin{array}{l}\text { terms of the bending stiffness matrix, } \\
i=j=1,2,6\end{array}$ & $S_{12}$ & ply shear strength \\
\hline$D_{c}$ & $\begin{array}{l}\text { bending stiffness of the superstiffener } \\
\text { element per unit width }\end{array}$ & $S_{C}$ & laminate shear strength \\
\hline$E I_{c}$ & longitudinal bending stiffness & $w_{0}$ & out of plane displacement \\
\hline$F_{12}$ & interaction term & $X_{i}$ & strength in the warp direction \\
\hline$F_{c}$ & longitudinal force applied to the centroid & $Y_{i}$ & $\begin{array}{l}\text { strength in the weft direction } \\
i=T \text { Tension }\end{array}$ \\
\hline$G_{x y}^{s w}$ & shear modulus of the stiffener web & $\alpha, \beta, \gamma, \delta$ & nondimensionnal parameters \\
\hline$K_{i}$ & buckling coefficient, $i=x, x y$, sh & $\sigma_{1}$ & stress in the warp direction \\
\hline$N_{i}$ & $\begin{array}{l}\text { load per unit length in the i direction, } \\
i=x, y, x y\end{array}$ & $\sigma_{2}$ & stress in the weft direction \\
\hline$N_{i}^{c r}$ & $\begin{array}{l}\text { critical load per unit length, } \\
i=x, y, w x, \text { sh }\end{array}$ & $\tau_{12}$ & shear stress \\
\hline
\end{tabular}




\section{Introduction}

A preliminary bibliographic study permits to obtain an overview of the subject, exploring several topics that the research works could be concerned of.

First of all this study has logically been oriented to aeronautic programs which concern the dimensioning of composite structures, and moreover when these affect fuselage parts. Composite manufacturing processes and their effects to the material properties are cited. Since composite structures show complex behaviours compared to metallic structures, finite element analysis is emerging as the reliable means to carry out dimensioning of the composite fuselage, taking into account corresponding theories. Some failure criteria will be described as basic phenomena to be validated by numerical methods. A walk-through postbuckling phenomenon is also provided as thin-walled structures made of carbon fibre reinforced plastics are able to tolerate repeated buckling without any change in their buckling behaviour [1,2]. Indeed, recent works are based on these aspects to validate cohesive failure of composite stiffened panels [3, 4].

\section{Aeronautic programs}

TANGO [5] was the first program in Europe to study a pressurised composite fuselage demonstrator leading to a full scale test of an A321 type fuselage section. This fuselage was made from frames and stringers and was dedicated to the commercial transport industry. The objective was to demonstrate technological feasibility of usable manufacturing processes: Automatic Fiber Placement (AFP), Resin Film Infusion (RFI), Liquid Resin Infusion (LRI), Resin Transfer Molding (RTM) and thermoplastic technologies.

The POSICOSS program [1] was undertaken at the same time as TANGO, but was followed by COCOMAT program [2] which undertook deeper studies of the dimensioning methods. These studies were mostly dedicated to increase the onset of degradation allowed during postbuckling of composite stiffened panels above the ultimate load.

A lot of different research fields have been investigated [6] as these programs involve a considerable number of industrial and academic partners. The final objective is to increase the Ultimate Load (UL), actually defined before the Onset of Degradation (OD), after the first ply failure occurs. Postbuckling of composite stiffened panels was particularly investigated. The aim of these works is to consider the structure safe after the degradation begins. Close form solutions of the buckling problem of composite stiffened panels are defined [7]. The specimen level has been studied for the failure of representative T-sections [4]. Also, representative curved panels have been modelled and tested to describe the buckling and postbuckling behaviour up to collapse [8].

Concerning the composite manufacturing processes, the main challenges of the "out of autoclave" processes [9] are said to be, first the qualification process (resin, fibre, fabric and process parameters) and second, the part geometry (porosity and defects induced by the process). However, a manufacturing process which uses the autoclave technique is time consuming and has high capital and operating costs $[10,11]$. Benefit of resin infusion processes like LRI is then to provide enough vacuum pressure for the removal of voids and thus performance of the manufactured part.

\section{Finite Element Analysis}

Methodologies. Various studies apply to the finite element analysis of aeronautic structures. Modelling methodologies can differ slightly within the same philosophy. There is always a global approach for modelling the entire part, and a local approach to more precisely study the area of interest $[3,4,12,13]$. Considering geometrical non linearity, the global model is generally linear and linear displacement fields are injected as boundary conditions in a local model.

Tests are often performed on representative parts as long as dimensioning is validated. For example Ambur and Rouse $[12,13]$ have built a test machine devoted to validating fuselage curved 
composite stiffened panels, including damage and a sandwich panel design, with pressurization and axial force loadings.

An obvious procedure is to conduct preliminary trade-off studies in order to determine appropriate boundary conditions in displacement and force. Boundary conditions in force can be introduced by different means, for example by using load actuators [12] or Multi-Points Constraints (MPC) and beams [4].

Validation. In a composite structure, a stress state at each ply is derived from calculated loads per unit length, and the corresponding finite element model is validated from a set of dimensioning criteria. These criteria are defined from the mechanism that has to be validated. At least failure criteria and buckling must be validated. A typical dimensioning validation is presented in Fig. 1. From the geometric model, a step by step approach is suggested. The first step is to create a mesh the closest to the geometric model, to produce a mechanical model. Then the Finite Element Analysis (FEA) divides the component study into subcomponents on which to apply an appropriate failure criterion. The post treatment permits to process results. If the specifications are satisfied, the geometric model is validated. If not, parameters are modified at each previous step.

Comparison of transverse shear integration. Modelling of composite structures is generally computed with Abaqus [3,8,14], Nastran/Patran [12,13] and Samcef. Transverse shear is not integrated in the same way into shell elements: generally Mindlin shells are used (Samcef, Nastran/Patran) and in some cases degenerated elements SC8R are implemented (Abaqus). The fact is that Classical Laminate Theory (CLT) does not include transverse shear effects in its formal form.

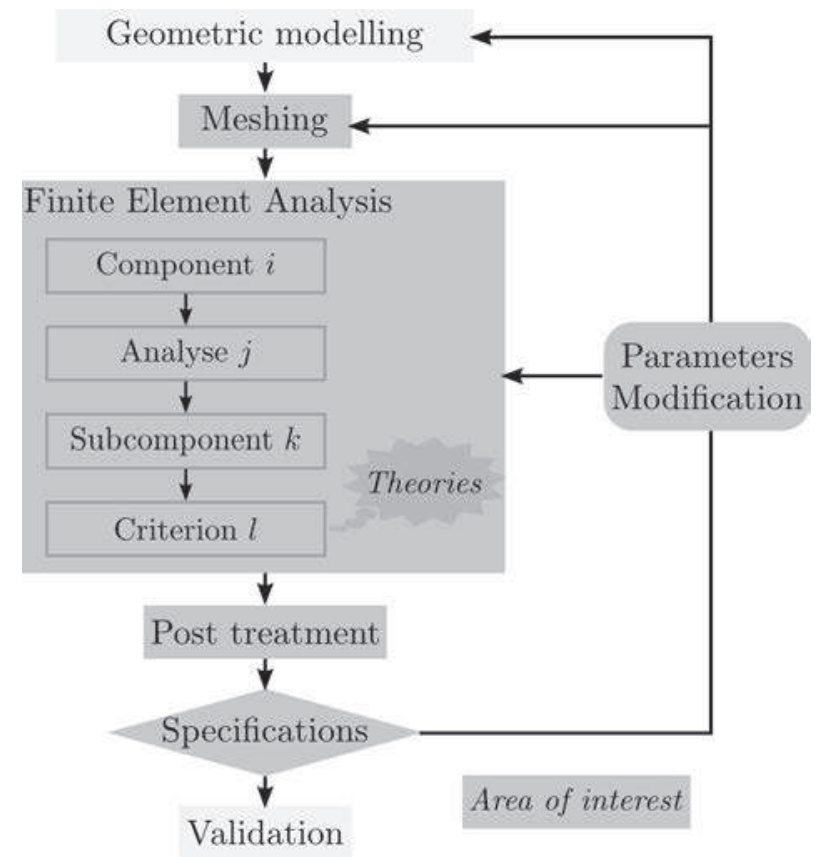

Figure 1 Typical dimensioning validation process

\section{Dimensioning criteria}

The validation steps of the finite element models are based on several dimensioning criteria to be determined. These dimensioning criteria are compared to a reference value and then a Reserve Factor (RF) is calculated. The design is validated when all RF are superior to 1.

Failure. A complete and validated methodology for predicting the behaviour of composite structures, including effects of damage, has not yet been fully achieved [14], due to their complex structure and to influences of the manufacturing processes. Fibre Reinforced Polymers (FRP) composite materials show a wide variety of failure mechanisms - fibre failure, matrix failure, buckling and delaminations - and should be considered as a structure rather than a material. 
Generally failure criteria are based on stresses, but criteria also exist based on strains, forces, displacements or rotations. However stress criteria are not appropriate to study damage progression, which is particularly true for delaminations. In this case classical fracture mechanics has often been used with success for the study of delaminations and decohesions. Its main disadvantage is that it involves the definition of pre-existing cracks and then can not serve to characterize damage initiation.

Numerous failure criteria for composite materials have been developed for more than 30 years, and can be classified according to whether they come from stress or fracture mechanics, whether they predict global failure or a specific failure mode, or whether they concern planar failure or through-thickness failure (interlaminar). Most often criteria are based on stress components of an individual layer of a laminate. Well-known criteria are given below. Fibre failure is most often considered with a maximal stress criterion, but also along with Hashin [15] in Eq. 1.

$$
\left(\frac{\sigma_{1}}{X_{T}}\right)^{2}+\left(\frac{\tau_{12}}{S_{12}}\right)^{2} \geq 1 .
$$

Apart from maximal stress and strain criterion, the Hashin and Roten proposition (Eq. 2) remains the simplest when dealing with matrix failure.

$$
\left(\frac{\sigma_{2}}{Y_{T}}\right)^{2}+\left(\frac{\tau_{12}}{S_{12}}\right)^{2} \geq 1
$$

Ply failure criteria are often used when delaminations can be neglected. The complete ply failure is predicted and failure mechanisms are not considered. This is the case for Yamada-Sun criterion [16] in Eq. 3 since $\mathrm{S}_{\mathrm{C}}$ is the ply shear strength measured into a symmetric cross-ply laminate.

$$
\left(\frac{\sigma_{1}}{X_{T}}\right)^{2}+\left(\frac{\tau_{12}}{S_{C}}\right)^{2} \geq 1
$$

This is also the case for interactive criterion such as Tsai-Wu [17] in Eq. 4 which is often criticized due to lack of phenomenological basis and origins of theories:

$$
\begin{aligned}
& \left(\frac{1}{\mathrm{X}_{\mathrm{T}}}-\frac{1}{X_{C}}\right) \sigma_{1}+\left(\frac{1}{\mathrm{Y}_{\mathrm{T}}}-\frac{1}{Y_{C}}\right) \sigma_{2}+\frac{\sigma_{1}^{2}}{X_{T} X_{C}}+\frac{\sigma_{2}^{2}}{Y_{T} Y_{C}}+\left(\frac{\tau_{12}}{S_{12}}\right)^{2}+2 F_{12} \sigma_{1} \sigma_{2} \geq 1 . \\
& \text { with } F_{12}=-\frac{1}{2} \sqrt{1 / X_{T} X_{C} Y_{T} Y_{C}} .
\end{aligned}
$$

Damage. Delamination mechanisms are dealt according to crack growth modes I, II and III (peeling, shearing and tearing respectively). Damage models are built to take into account the performance loss caused by damage, by defining a damage factor to model a progressive ply damage.

The achievement of this kind of model is difficult since damage factors could be adjusted for FE results to give a valid solution without experimental correlation. For delamination and decohesion, fracture mechanics is used by splitting the damaged region into two substructures plus one contact zone. Up until today, these methods with non linear approaches have been used with success in Abaqus/Standard and MSC.Marc, to control joining between the two surfaces. 
Also, key length scale at an under-ply, ply, laminate, structure and components levels ; implies a variety of behaviours and failure mechanisms. Moreover composite failure modes are interactive which means that a given mechanism can delay or intensify the development of other failure mechanisms. Consequently damaged regions, manufacturing defects, structural defects and probabilistic variation of properties should be considered in the dimensioning of composite structures.

Buckling. The buckling general expression in bi-axial loading [18] enables building adapted criteria from critical loads per unit length taking into account boundary conditions:

$$
\mathrm{D}_{11} \frac{\partial^{4} w_{0}}{\partial x^{4}}+2\left(D_{12}+2 D_{66}\right) \frac{\partial^{4} w_{0}}{\partial x^{2} \partial y^{2}}+D_{22} \frac{\partial^{4} w_{0}}{\partial x^{4}}=N_{x} \frac{\partial^{2} w_{0}}{\partial x^{2}}+N_{y} \frac{\partial^{2} w_{0}}{\partial y^{2}}
$$

An example is drawn for a composite stiffened panel with T-sections in buckling, with simple support [7] in Table 1. Closed form solutions of this study are adapted to the dimensioning validation process suggested in Fig. 1. Some variables need to be defined in Eq. 7 [19,20].

\begin{tabular}{|l|l|}
\hline \multicolumn{2}{|l|}{ Component : Composite Stiffened Panel - Analysis : Buckling } \\
\hline Subcomponent 1 : Skin & $R F_{p x}=\frac{N_{x}^{c r}}{-N_{x}}$ with $N_{x}^{c r}=K_{x} \frac{\pi^{2}}{b^{2}} \sqrt{D_{11} D_{22}}$ \\
\hline Criterion 1 : Normal Buckling & $R F_{p x y}=\frac{N_{x y}^{c r}}{\left|N_{x y}\right|}$ with $N_{x y}^{c r}=K_{x y} \frac{\pi^{2}}{b^{2}} \sqrt[4]{D_{11} D_{22}^{3}}$ \\
\hline Criterion 2 : Shear Buckling & $\frac{1}{R F_{p b}}=\frac{1}{R F_{p x}}+\frac{1}{\left(R F_{p x y}\right)^{2}}$ \\
\hline $\begin{array}{l}\text { Criterion 3 : Normal-Shear buckling } \\
\text { interaction }\end{array}$ & $R F_{w b}=\frac{N_{w x}^{c r}}{-N_{w x}}$ with $N_{w x}^{c r}=\frac{12}{b^{2}}\left(D_{66}-\frac{D_{26}^{2}}{D_{22}}\right)$ \\
\hline Subcomponent 2: Stiffener & $R F_{c b}=\frac{P_{c r}}{-F_{c}}$ with $P_{c r}=\frac{P_{e}}{1+\left(P_{e} / A_{s w} G_{x y}^{s w}\right)}$ and $P_{e}=\frac{\pi^{2} E I_{c}}{a^{2}}$ \\
\hline Criterion 1 : Local Buckling & $R F_{s b}=\frac{N_{s h}^{c r}}{\left|N_{x y}\right|}$ with $N_{s h}^{c r}=K_{s h} \frac{\pi^{2}}{a^{2}} \sqrt[4]{D_{c}^{3} D_{22}}$ \\
\hline Component : Skin + Stiffener & $\frac{1}{R F_{c s}}=\frac{1}{R F_{c b}}+\frac{1}{\left(R F_{s b}\right)^{2}}$ \\
\hline Criterion 1 : Normal buckling & $\begin{array}{c}\text { Criterion 3 : Normal-Shear buckling } \\
\text { interaction }\end{array}$ \\
\hline
\end{tabular}

Table 1 Dimensioning criteria in buckling of composite stiffened panels with T-sections

$$
\begin{aligned}
& \alpha=\sqrt[4]{\frac{D_{22}}{D_{11}}}, \quad \beta=\frac{D_{12}+2 D_{66}}{\sqrt{D_{11} D_{22}}}, \quad \gamma=\frac{D_{16}}{\sqrt[4]{D_{11}^{3} D_{22}}}, \quad \delta=\frac{D_{26}}{\sqrt[4]{D_{11} D_{22}^{3}}} \\
& K_{x}=2(1+\beta)-2\left(\beta+3+2 \gamma^{2}\right) \frac{(\gamma+3 \delta)^{2}}{(\beta+3)^{2}}-4\left(\delta+2 \gamma^{3}-\beta \gamma\right) \frac{(\gamma+3 \delta)^{3}}{(\beta+3)^{3}} \quad \text { for } \quad|\gamma| \text { and }|\beta|<4 \\
& K_{x y}=3.42+2.05 \beta-0.13 \beta^{2}-1.79 \gamma-6.89 \delta+0.36 \beta(2 \gamma+\delta)-0.25(2 \gamma+\delta)^{2} \\
& K_{s h}=K_{x y} \text { with } D_{22}=D_{c}=E I_{c} / b
\end{aligned}
$$




\section{Postbuckling and structural failure}

Works dealing with postbuckling phenomenon that have been achieved within the framework of the COCOMAT and POSICOSS programs $[1,2]$ have naturally led to the study of structural failure of integrated stiffeners onto composite panels. Results of some studies carried out at the DLR [8] relating to the failure of stiffeners show that the most significant failure mode observed during postbuckling tests consists of a cohesive failure between the stiffeners and the skin. That does not only perform as a skin-stiffener debonding, but also (in the case of excellent assembly) as delaminations and failure into the skin or the stiffeners flanges. Moreover blade ply failure in the Tsection stiffener webs is observed at collapse [8].

Thus some authors [4] suggest a methodology implying a searching phase for the cohesive failure site, via a stress failure criterion involving interlaminar and through-thickness stresses. Intralaminar damage of the ply is also assessed in order to take into account ply damage mechanisms such as matrix cracking and fibre failure. Then the cohesive failure of the structure can be described with an energetic damage criterion to assess the crack propagation [3], where one makes the assumption of an existing crack initiation. VCCT (Virtual Crack Closure Technique) and VCE (Virtual Crack Extension) methods are generally used to assess fracture mechanics [14].

According to the industrial experience feedback, the structural failure of the integrated structures seems to occur without even going into a postbuckled state. Moreover it appears that cohesive failure cannot be treated as bonding and that it is necessary to break away the searching phase of the crack initiation from the crack propagation phase. It is however important to underline that all the computational methods suffer from the variability of input properties. Variability of tensile strength and through-thickness shear strength, which in addition have to be determined by experimentation, implies for example that there is a scatter in the stress failure criterion of about $25 \%$ [4].

Also, the real geometry linked with the manufacturing process has a great influence which must be assessed [3]. Other geometrical variations are difficult to take into account numerically, as for example the edge geometry idealization of stiffener flanges leading to stress concentration areas where the mesh density has a strong influence on the final results [4].

All of these parameters seem to have a considerable influence on the cohesive failure of integrated structures. Their variability will have to be integrated as far as possible into the computational methods; otherwise it will be taken into account for comparison with experimental results. For example, because of the transverse tensile strength variability, the influence of the ply drop-offs is difficult to assess numerically [4]. In order to describe a loading case close to reality, a global/local approach is carried out to automatically transpose the local method to other areas of the global model.

\section{Cohesive failure of integrated structures}

Cohesive failure issues of integrated structures appear as the study of a phenomenon directly introduced by the integration of functions. In design, some parts are directly integrated into the end product, unlike metal products where there is a close match between a design function and a component and where all parts are finally assembled after having been manufactured separately.

Composite material manufacturing processes make it possible to put parts together by co-curing or co-bonding. In the case of the LRI process, constituting parts of the structure are integrated using preformed dry reinforcements to be cross-linked at the same time, thus with an assembly concept equivalent to co-curing. The resin interface between the parts plays the role of a link between them, which is identical between each ply of the global structure.

The cohesive failure behaviour of the structure is mainly governed by a damage phenomenon that generally occurs at the flange-skin interface level, most often initiated by a geometrical singularity. The usual approach to study this phenomenon is to make the stiffeners carry the load after the skins buckle, which means the flange-skin interface becomes a load transmission zone which must withstands the new load state. 


\section{Conclusion}

Works to follow this preliminary bibliographic study come from the requirement of numerically and experimentally validating integrated structures and from the need to justify LRI manufactured structures without rivets.

First of all, through-thickness properties need to be obtained in order to constitute input data of the numerical models, in addition to standard in-plane properties. With an appropriate approach, these permit to assess the cohesive failure and damage mechanisms into the numerical models. Woven fabric plies properties are used.

Next, experimental investigation at a specimen scale allows reliable comparison between experimental and computational results. Also a test of a representative part describing a behaviour close to the global aircraft is set up. That makes it possible to check the validity of the approach.

A global/local approach will finally enable the developed computational methods to be applied to various areas of interest. 


\section{References}

[1] R. Zimmermann and R. Rolfes. Posicoss - improved postbuckling simulation for design of fibre composite stiffened fuselage structures. Composite Structures, 73:171-174, 2006.

[2] R. Degenhardt, R. Rolfes, R. Zimmermann, and K. Rohwer. Cocomat material exploitation of composite airframe structures simulation of postbuckling and collapse. Composite Structures, 73:175-178, 2006.

[3] J. Bertolini. Contribution à l'analyse expérimentale et théorique des ruptures de structures composites en post-flambement par décollement des raidisseurs. PhD thesis, UPS, 2008.

[4] A.C. Orifici, S.A. Shah, I. Herszberg, A. Kotler, and T. Weller. Failure analysis in postbuckled composite t-sections. Composite Structures, 86:146-153, 2008.

[5] L. Fielder, S. Barré, J.I. Molina, and C. Voto. Tango composite fuselage platform. SAMPE Journal, 39(1):57-63, January/February 2003.

[6] 2nd conference on buckling and postbuckling behaviour of composite laminated shell structures with cocomat workshop. September 2008.

[7] J.E. Herencia, P.M. Weaver, and M.I. Friswell. Optimization of long anisotropic laminated fiber composite panels with t-shaped stiffeners. AIAA Journal, 45(10):2497-2509, October 2007.

[8] R. Zimmermann, H. Klein, and A. Kling. Buckling and postbuckling of stringer stiffened fibre composite curved panels - tests and computations. Composite Structures, 73:150-161, 2006.

[9] K. Mason. Autoclave quality outside the autoclave? High Performance Composites, March 2006.

[10]L.W. Davies, R.J. Day, D. Bond, A. Nesbitt, J. Ellis and E. Gardon. Effect of cure cycle heat transfer rates on the physical and mechanical properties of an epoxy matrix composite. Composites Science and Technology, 67:1892-1899, 2007.

[11]M.G. Bader. Selection of composite materials and manufacturing routes for cost-effective performance. Composites: Part A, 33:913-934, 2002.

[12]D.R. Ambur and M. Rouse. Design and evaluation of composite fuselage panels subjected to combined loading conditions. Journal of Aircraft, 42(4):1037-1045, 2005.

[13]M. Rouse, D.R. Ambur, B. Dopker, and B. Shah. Response of composite fuselage sandwich side panels subjected to internal pressure and axial tension. Journal of Aircraft, 43(5):1440 1447, 2006.

[14]A.C. Orifici, I. Herszberg, and R.S. Thomson. Review of methodologies for composite material modelling incorporating failure. Composite Structures, 86:194-210, 2008.

[15]Z. Hashin. Failure criteria for unidirectional fiber composites. Journal of Applied Mechanics, 47:329-334, 1980.

[16] S.E. Yamada and C.T. Sun. Analysis of Laminate Strength and its distribution. Journal of Composite Materials, 12:275-284, 1978.

[17] S.W. Tsai and E.M. Wu. A general theory of strength for anisotropic materials. Journal of Composite Materials, 5:58-80, 1971.

[18]JM. Berthelot. Matériaux Composites - Comportement mécanique et analyse des structures 4ème édition. Editions TEC\&DOC, 2005.

[19]M.P. Nemeth. Importance of Anisotropy on Buckling of Compression-Loaded Symmetric Composite Plates. AIAA Journal, 24:1831-1835, 1986.

[20]P.M. Weaver. Approximate Analysis for Buckling of Compression Loaded Long Rectangular Plates with Flexural/Twist Anisotropy. Philosophical Transactions of the Royal Society of London, Series A: Mathematical and Physical Sciences, 462:59-74, 2006. 
New Approaches in the Manufacturing Processes

doi:10.4028/www.scientific.net/AMM.62

Numerical Modelling of a Composite Fuselage Manufactured by Liquid Resin Infusion

doi:10.4028/www.scientific.net/AMM.62.49 